\title{
HISTORY \\ From medical manners to moral reasoning: An historical overview of bioethics in the University of Cape Town's Faculty of Health Sciences
}

\author{
Solomon R Benatar, David Benatar
}

The history of bioethics in the Faculty of Health Sciences of the University of Cape Town follows a similar pattern to elsewhere. At first, bioethics received little formal attention, but there has been a flowering of interest over the last few decades. There has also been a shift from a professionally insular view of bioethics to one informed by non-medical disciplines. While this pattern is to be found in many parts of the world, there are some distinctive, but not unique, features of bioethics at South Africa's oldest Medical School.

S Afr Med J 2012;102(6):406-408

\section{The early years: $1922-1984$}

Snippets of the early history of medical ethics in the Faculty are available. Much ethical instruction was implicit and conveyed by the example of medical educators and practitioners. The regulatory framework, enhanced by the establishment in 1928 of the South African Medical and Dental Council (now the Health Professions Council of South Africa (HPCSA)), would also have fostered, and responded to breaches of, professional and ethical standards.

From 1945 some formal instruction in medical ethics was offered by $\mathrm{Dr} C$ Elliott who gave about 6 lectures in 'Medical ethics' to sixth-year students. Dr K Bremer lectured on 'Methods in general practice', including the 'relationship and conduct towards patients, the public, local authorities, the State and colleagues'. Dr Z de Beer assumed responsibility for both sets of lectures from 1950 until 1953; from 1954 to 1959 these were given by Dr R Impey. Thereafter and until 1983 successive deans were responsible for lectures which, under Professor Bromilow-Downing, were designated as 'Conduct of medical practice and medical ethics. ${ }^{1}$

This model of medical ethics was common worldwide. Instruction was provided by a doctor, often a senior figure. Teaching consisted of transmitting professional norms enshrined in codes such as the Hippocratic Oath to students. There was little critical reflection on these norms, or how to think about contested ethical issues.

This began to change in the 1960s in the USA, ${ }^{2,3}$ and in the following decade in South Africa. The first manifestations of change were in scholarly interest rather than in teaching, with attention devoted to contested moral questions, such as abortion ${ }^{4}$ and euthanasia. ${ }^{5}$

Early scholarly interest in bioethics was pioneered by theologians. Philosophers, lawyers and others soon took up these issues in greater depth. Perhaps because such academic work was instigated by nonmedical scholars it had little early impact on the medical profession. Nor did it evoke much public discussion. An exception to this was

Solomon Benatar is Emeritus Professor of Medicine, University of Cape Town and Professor in the Dalla School of Public Health and the Joint Center for Bioethics, University of Toronto. David Benatar is Professor and Head, Department of Philosophy, University of Cape Town. debate about the definition of death and the harvesting of hearts following the first heart transplant at Groote Schuur Hospital (GSH) in $1967 .^{6}$

In 1977 the death of Steve Biko while in police detention generated considerable professional and public ethical discussion of a different kind. Whereas organ transplantation raises complex ethical questions that are difficult to resolve, there was no moral complexity surrounding Mr Biko's death. Instead, there were clear ethical breaches on the part of the doctors who were responsible for him. Professors Frances Ames and Peter Folb from the University of Cape Town, together with Professors Trefor Jenkins and Phillip Tobias from the University of the Witwatersrand, pursued disciplinary action against the doctors. This case played an important role in sensitising the medical profession to medical ethical issues in South Africa.

Given such events and the repression that characterised South Africa, it is unsurprising that another shift in bioethical thinking internationally would have resonated in the Faculty, even though not widely in 'white' South African society. This shift, towards a greater focus on patients' rights and the questioning of medical authority, went hand in hand with greater emphasis on patient autonomy and resistance to medical paternalism.

In the early 1980s it was recognised that the teaching of medical ethics required reconsideration, and in 1984 two Religious Studies scholars, Professor Charles Villa-Vicencio and Professor James Leatt, lectured to fifth-year students. The dean recognised that staff should use clinical opportunities to teach about ethical issues, ${ }^{7}$ although none of the medical staff at that time had significant formal education in scholarly aspects of medical ethics.

\section{Recent decades: 1985 to the present}

The year 1985 was a significant one. An informal Bioethics Unit was established in the Department of Medicine to serve as a resource for the Faculty. In that year the unit held the first of the Faculty's bioethics symposia, which were well attended and their proceedings published. ${ }^{8}$

The Unit also arranged weekly meetings, some of which had an educational goal (to introduce healthcare professionals to academic ways of thinking about ethics and ethical issues). Others discussed specific cases and problems brought by various departments and units in the Faculty of Medicine or GSH.

From its inception, the Unit was multidisciplinary and included members of the Faculty, doctors, nurses and chaplains from GSH, as well as academics from non-medical disciplines, such as law and social sciences. Philosophers (from UCT, Stellenbosch University 
and the University of the Western Cape (UWC)) were particularly well represented.

In 1992 UCT formally approved what became known as the Bioethics Centre, the first such centre in South Africa. It relocated to the dean's office in 2008, under the continued directorship of Solomon Benatar. In 2009 the Centre repositioned under the joint auspices of the Faculty of Health Sciences and the Department of Philosophy in the Faculty of Humanities. This officially recognised the long-standing collaboration between Medicine and Philosophy, exemplified by joint planning and teaching, since 1989, of the undergraduate $\mathrm{MB} \mathrm{ChB}$ bioethics curriculum.

The Centre's activities were initially funded from within the Department of Medicine and from personal donations. Subsequent funding came through generous grants from the USA National Institutes of Health's Fogarty International Center (2001 - 2011). Since 2008, the Faculty of Health Sciences has annually contributed to staffing and administrative costs.

\section{Activities of the Bioethics Centre}

There are 3 core activities, which frequently intersect: education, research, and clinical consultations and other services.

\section{Education}

Teaching is provided to undergraduate $\mathrm{MB} \mathrm{ChB}$ students and occasionally to other undergraduates in the Faculty. In the MB ChB programme this is spread over several years. In the third year, students are introduced to academic thinking about ethics and learn about foundational ideas such as autonomy and informed consent, proxy decision making for incompetent patients, confidentiality and truthtelling. In the fourth year they are taught to think more critically about issues such as abortion, end-of-life decisions, resource allocation and conflicts of interest. In the final year they have 2 lectures on the doctor-patient relationship and the HPCSA codes, and small-group ethics case discussions. Students are examined on bioethics in the third and fourth years only.

The course comprises 22 contact hours, excluding occasional less formal exposure. While the content and academic rigour are greater than in the past, time constraints limit what can be achieved. We aim to help students realise that ethics is not merely a matter of opinion - whether received or otherwise - and to introduce them to ways of thinking critically and intelligently about what ought to be done in difficult situations. The aim is to be academically rigorous but practically grounded, moving from a theoretical introduction in a practical direction; first discussing principles, then selected practical problems, and finally specific cases that arise in the students' own experiences.

While some believe or hope that including bioethics in the formal curriculum will make students more ethical when they become doctors, it is naïve to think that formal teaching will uniformly have this effect. No amount of formal instruction will improve students' attitudes to ethics if they are not motivated to behave properly. However, learning about ethics may sensitise conscientious people and enable them to think and act better when confronted with difficult problems. The informal curriculum also plays a role - students learn from the example set by their clinical teachers. That example is generally good; when it is not, ${ }^{9}$ a further teaching opportunity is provided.

Postgraduate bioethics education has been less systematic. Several ad hoc courses (including a National Bioethics course) and Faculty symposia have been held. Regular educational sessions are provided within the Department of Medicine formal academic meetings at several hospitals (GSH, New Somerset, J F Jooste, Victoria and
2 Military). At these meetings, students and staff are provided opportunities to engage with and manage the ethical dilemmas faced in medical practice. Practically oriented lectures and seminars are also provided in response to invitations from other clinical divisions, such as psychiatry, surgery, ophthalmology, obstetrics and gynaecology, human genetics and family medicine, as well as at many local and national medical conferences and workshops.

Theodore Fleischer (Bioethics) and Anne Pope (Faculty of Law) jointly developed and taught a course on Law and Medicine in the UCT Faculty of Law.

The Centre offered an MPhil in Bioethics to a single cohort of students. Two graduates (Lesley Henley and Paul Roux) contribute valuably to bioethics in the Faculty.

A larger educational and capacity-building Postgraduate Diploma in International Research Ethics Network for Southern Africa (IRENSA) was supported by grants (about US\$2 million) from the USA National Institutes of Health's Fogarty International Center from 2001 to 2011. Its goal was to develop sustainable capacity in international research ethics in southern Africa. Teachers comprised multidisciplinary scholars from the Universities of Cape Town, Stellenbosch, London, Toronto, Chicago, North Carolina, Yaoundé, Zimbabwe, and the Ethics Institute of South Africa. Between 2003 and 2010, 97 mid-career professionals from South Africa and eight other African countries participated.

Research ethics committees (RECs) throughout South Africa (including UCT's), and in other African countries, benefited from having members participate in the IRENSA programme. In addition to the diploma course, annual 2-day courses since 2002 have attracted almost 1000 participants.

Members of the Centre have participated in the activities of other bioethics centres in South Africa, e.g. Stellenbosch University's Master's course on Applied Ethics. More recently the Centre assisted this university in its successful application for a Fogarty Grant modelled on the UCT IRENSA programme. The Fogarty Center awarded 2 sub-grants of US\$50 000 each to IRENSA graduates for capacity building in research ethics at UWC and in Kenya.

\section{Research}

Research has fallen into 2 main categories: (i) projects undertaken by individuals or groups within the Centre; and (ii) work with other departments to explicate and manage ethical dilemmas they have faced.

Areas of special research interest to individual members of the Centre have included: (i) ethical responsibilities in international, cross-cultural collaborative research (for example defining and avoiding exploitation, new approaches to standards of care, balancing harms and benefits, developing partnerships and reasoned approaches to the application of universal principles in local contexts); (ii) broadening the bioethics discourse beyond interpersonal ethics to include consideration of public health ethics, global health and the societal forces giving rise to disparities that shape health at the level of whole populations; (iii) controversies in surgery (for example limb and face transplantation, cosmetic surgery, circumcision and other genital surgery); (iv) end-of-life decision making (including the right to die and suicide); ( $v$ ) bioethics and human rights; (vi) teaching medical ethics; (vii) dilemmas in relation to HIV/AIDS; (viii) the place of universal declarations; $(i x)$ ethics of animal experimentation and the use of animals in other ways that impact on human health; (x) reproductive ethics; (xi) genetic ethics; (xii) professional attitudes to informed consent for a range of medical procedures; (xiii) seeking fairness in the distribution of resources; and (xiv) the linkages between bioethics and law. This research has resulted in many peer- 
reviewed publications and invited presentations at conferences locally and abroad.

Collaborative work with other departments has included several studies aimed at providing reasoned, accountable, publicly accessible approaches for allocation of limited resources. The first study, undertaken jointly with the UCT Neurosurgery Department, led to a policy for allocating scarce intensive care unit (ICU) resources for head-injured patients. ${ }^{10}$ This policy was subsequently approved for regional implementation by the Department of Health of the Western Cape. It provided the first local example of how multiple relevant stakeholders could set priorities in a transparent and accountable manner, and led to the Western Cape Department of Health requesting assistance with developing priority setting mechanisms.

Most recently a new policy for priority setting in the renal dialysis and transplant programme was completed with extensive assistance from the Bioethics Centre. Work is under way with Professor Andrew Argent at the Red Cross Children's Hospital to develop a Paediatric ICU admission policy. A major study evaluating changing trends in expenditure on HIV/AIDS in South Africa and the extent to which care for such patients is eclipsing equitable access to healthcare for patients with other diseases has been completed.

\section{Clinical consultations and other services}

An important objective of the Bioethics Centre has been to develop a clinical consultative service, and to foster interactive dialogue between bioethicists, health policy makers, professional associations, practising health professionals, healthcare administrators and the public, and to be a resource for advice and assistance.

For reasons of staff availability the clinical consultative service has not been offered on a formal basis around the clock throughout the academic complex, but many (and ongoing) requests for consultation receive attention, some within the wards and others through discussions with interested groups during seminars arranged around specific topics. Recently the GSH Administration has shown interest in developing a clinical ethics consultation committee within this hospital complex.

The extent of wider interactions with colleagues is reflected in invitations to contribute to many and varied national and international activities. Nationally, contributions were made to the Parliamentary Commission on 'Abortion' and to the South African Law Commission's Reports on 'Euthanasia'. Two statements on these issues were published in the SAMJ. ${ }^{11,12}$ The (previously mentioned) advice to the Western Cape Government's Department of Health was extended in collaboration with Professor Douglas Martin, of the Joint Center for Bioethics at the University of Toronto, through a series of seminars delivered in Cape Town and in the Western Cape Health Region. The purpose was to enable managers and clinicians to develop explicit and accountable priority-setting processes.

Members of the Center have also given support to other organisations and institutions. These include assistance to the Medical Research Council (MRC) Research Ethics Committee in writing an updated set of MRC Guidelines for Medical Research in South Africa and chairing the Interim National Research Ethics Committee that formulated a set of National Research Ethics Guidelines.

Internationally, assistance has been given, inter alia, to Médecins sans Frontières in its work on justice in the allocation of its resources, the Ethics Working Group of Family Health International's HIV
Prevention Network, the International Association of Bioethics, and the Standing Committee on Ethics in the Canadian Institutes of Health Research.

\section{Research ethics in the Faculty of Health Sciences}

The UCT Faculty of Health Sciences Human and Animal RECs are responsible for ensuring that research conducted in the Faculty complies with current requirements. These committees function under the auspices of the dean's office and although they have no direct links to the Bioethics Centre, several of our members have served on them and have made contributions to improvements in their processes, structure and management. Between 1999 and 2010 the annual number of research ethics protocols evaluated by the Human REC almost doubled from 323 to 603 .

\section{Conclusion}

The development of bioethics in the Faculty over the last few decades follows a pattern that has also characterised bioethics at medical schools in other parts of the world: growth, increased formalisation, and a shift from an insular view to one informed by non-medical disciplines. What is distinctive, even though not unique, about bioethics in Cape Town is the especially close relationship between medicine and philosophy. There are all too many places where doctors and philosophers cannot or do not engage with one another. In these places philosophers talk about bioethical issues without any understanding of medicine or any awareness of the practical realities, while doctors talk about ethics in ignorance of this field of philosophy. In the Faculty of Health Sciences, doctors, philosophers and others have collaborated closely. This welcome arrangement is not unique, but it is sufficiently uncommon to be noteworthy.

The centenary anniversary of the Faculty is an appropriate time not only to examine its history, but also to look towards its future. While there has been much bioethics activity in the Faculty over the last few decades, the great majority of the work has been done by those who have taken it on over and above their regular work. While this is not an unusual feature of academic life, it should be viewed as a supplement to more sustainable arrangements for the continued growth of bioethics.

\footnotetext{
1. Faculty of Medicine Handbooks. Cape Town: University of Cape Town, 1945-1983.

2. Jonsen AR. The Birth of Bioethics. New York: Oxford University Press, 1988.

Walter JK, Klein EP, eds. The Story of Bioethics: From Seminal Works to Contemporary Explorations. Washington, DC: Georgetown University Press, 2003.

Oosthuizen GC, Abbot G, Notelovitz M. Great Debate: Abortion in South Africa. Cape Town: Howard Timmins, 1974

Oosthuizen GC, Shapiro H, Strauss S. Euthanasia. Cape Town: Oxford University Press, 1978.

6. Oosthuizen GC. The Ethics of Tissue Transplantation. Cape Town: Howard Timmins, 1972.

7. Dall G. 'Opening address.' In: Benatar SR, ed. Ethical and Moral Issues in Contemporary Medical Practice: Proceedings of a University of Cape Town Faculty of Medicine Symposium, Cape Town: Practice: Proceedings of a University of Cape Town Fa

Department of Medicine, University of Cape Benatar SR, ed. Faculty of Medicine Symposia on Bioethics. Cape Town: UCT Department of Medicine, 1986, 1987, 1988, 1992 and 1997.

9. Vivian LMH, Naidu CS, Keikelame MJ, Irlam J. Medical students' experiences of professional lapses and patient rights abuses in a South African health sciences faculty._Acad Med 2011;86(10):1282-1287. 10. Benatar SR, Fleischer TE, Peter JC, Pope A, Taylor A. Treatment of head injuries in the public sector in South Africa. S Afr Med J 2000;90:790-793.

11. UCT Bioethics Centre. Statement: Withholding and withdrawing life-sustaining therapy. S Afr Med J 1994;84:254-257.

12. Benatar SR, Abels C, Abratt R, et al. Abortion: some practical and ethical considerations. S Afr Med J 1994;84:469-472.
} 